\title{
COMO AS ESCOLAS FAZEM AS POLÍTICAS: ATUAÇÃO EM ESCOLAS SECUNDÁRIAS
}

\author{
Elton Oliveira de Moura ${ }^{(*)}$ \\ Rafael Ferreira de Souza Honorato ${ }^{(* *)}$ \\ Ramon Olímpio de Oliveira ${ }^{(* *)}$ \\ Maria Zuleide da Costa Pereira ${ }^{(* * *)}$
}

BALL, Stephen J.; MAGUIRE, Meg; BRAUN, Annette. Como as escolas fazem as políticas: atuação em escolas secundárias. Trad.: Janete Bridon. Ponta Grossa: Editora UEPG, 2016. 332p.

A obra resenhada é uma tradução do livro How schools do policy: policy enactments in secondary schools, lançado originalmente em 2012, por Stephen J. Ball, Meg Maguire e Anette Braun, docentes do Instituto de Educação da University College London, que lecionam o componente de Sociologia da Educação e investigam as políticas educacionais.

Como as escolas fazem a política propõe para as pesquisas em educação, com ênfase nas políticas educacionais, a erradicação do binário política-prática. O objetivo do autor e das autoras ${ }^{1}$ é desenvolver e ampliar a teoria da atuação das políticas (policy enactment), com base na premissa: “As políticas não costumam dizer o que fazer, elas criam circunstâncias em que as opções disponíveis para decidir o que fazer são reduzidas ou alteradas” (BALL, 1994, p. 19, tradução nossa), contribuindo com as Teorias da Educação através da exclusão do termo/conceito/ideia de “implementação” nas pesquisas educacionais, por entender que tal forma de perceber o processo da política em ação torna os sujeitos responsáveis pela atuação dessa política no contexto da escola meros operários, bem como desconsidera o processo de interpretação, reinterpretação, tradução, criação e recriação que essas políticas passam.

\footnotetext{
${ }^{(*)}$ Doutorando em Administração no Programa de Pós-graduação em Administração da Universidade Federal da Paraíba. E-mail: eltonom@gmail.com.

${ }^{(* *)}$ Doutorando em Educação no Programa de Pós-graduação em Educação da Universidade Federal da Paraíba. E-mail: rafaelhono@gmail.com.

${ }^{(* * *)}$ Doutorando em Educação no Programa de Pós-graduação em Educação da Universidade Federal da Paraíba. Email: ramonolimpio@gmail.com.

${ }^{(* * *)}$ Professora Titular do Centro de Educação da Universidade Federal da Paraíba, Professora do quadro permanente do Programa de Pós-graduação em Educação.E-mail: mzul@uol.com.br.

${ }^{1}$ Utilizamos o termo "autor e autoras" e suas variantes com o objetivo de proporcionar tratamento equitativo entre mulheres e homens, a partir da utilização da linguagem sem generalizações, evitando a aplicação sexista do discurso. Assumimos esse posicionamento político e pedagógico para destacar as mulheres em contraponto à linguagem institucionalizada pelas normas cultas de língua portuguesa que ratificam o masculino genérico para referir-se a todas as pessoas.
} 
Nesse sentido, o livro se destina aos formuladores de políticas, ao ponto que destaca como as escolas são locais únicos de atuação das políticas, o que por vezes é ignorado pelo formuladores de políticas; aos executores de políticas, para falar com aqueles que atuam nas escolas e destacar as diferentes formas pelas quais as políticas são traduzidas na prática; e, por fim, ao acadêmicos, com o intuito de "problematizar" a forma como são feitos os estudos sobre implementação de políticas em educação.

Para a discussão da teoria da atuação, o livro apresenta um estudo empírico do trabalho de política em quatro escolas secundárias da Inglaterra, onde se encontrou uma diversidade de políticas atuantes em cada escola. O livro é dividido em sete capítulos que apresentam as nuances da atuação política nas escolas e os processos de interação, negociação e interpretação que envolvem a produção do "fazer” política nas escolas.

No primeiro capítulo, Fazendo pesquisa sobre atuação de política, Ball, Maguire e Braun (2016, p. 18-19) destacam que a atuação se constitui como a capacidade de perceber a política como “ um aspecto dinâmico e não linear de todo o complexo que compõe o processo da política, do qual a política na escola é apenas uma parte”. As políticas são produzidas em várias instâncias, com por exemplo, as escolas, autoridades locais, nacionais e internacionais. Umas são obrigatórias, outras são sugestões, outras legíveis (prescritivas) e outras ainda escrevíveis (orientações), ou simplesmente viram artefatos da moda que nem sempre têm sua trajetória clara.

A relevância do estudo se deve ao enfoque inovador que recorreu às teorias da sociologia para colocar em evidência os contextos e as formas complexas pelas quais a escola cria artefatos para lidar com as inúmeras políticas colocadas para ela, seus professores, alunos e demais sujeitos, afetados direta ou indiretamente. Segundo o autor e as autoras, o livro é "sobre como as escolas ‘fazem’ política, especificamente sobre como as políticas tornam-se ‘vivas’ e atuantes (ou não) nas escolas [...]”.

Ainda no primeiro capítulo, é apresentado o tempo do estudo, que durou dois anos e meio de pesquisa através do estudo de caso de quatro escolas secundárias. Para compreender o processo de construção das categorias interpretação, reinterpretação, tradução, criação e recriação, que Ball, Maguire e Braun (2016) apresentam, é preciso considerar que existe um ponto de partida e uma trajetória, além de outros colaboradores. Em 1987, Ball já tinha resistência a aceitar o termo “implementação” em seus escritos, o que se evidencia na obra The Micro-Politics of the School: Towards a Theory of School Organization, na qual fez uma crítica à marginalização das análises da 
micropolítica destacando que "actores definen, interpretan y menejan las situaciones con las que se enfrentan” (BALL, 1989, p. 42).

Existe nessa obra a ampliação da ideia de Bowe, Ball e Gold (1992) e Ball (1994), do Ciclo Contínuo de Políticas, a superação do termo "implementação" e a construção de uma teoria da atuação com foco no contexto da prática, analisando os “efeitos localizados” (BALL, 1994) de primeira e segunda ordem. Para isso, nessa nova obra Ball, Maguire e Braun (2016, p. 13) apresentam um conceito de política, que não estava tão claro nas obras anteriores, a política como “textos e ‘coisas' (legislação e estratégias nacionais), mas também como processos discursivos que são complexamente configurados, contextualmente mediados e institucionalmente prestados”.

Fechando o capítulo evidenciamos as diversas e complexas influências, além de recursos teóricos, tais como: discurso e governamentalidade (FOUCAULT, 1979), teoria literária (BARTHES, 1970; HALL, 1997), teoria do ator-rede (TAR) - (LAW, 2008; FENWICK; EDWARDS, 2010) e as análises críticas do discurso (FAIRCLOUGH, 1989), entre outros. Existem elementos novos que foram adicionados para dar conta de construir a teorização acerca da atuação: o material, o interpretativo e o discursivo, por exemplo, são três dimensões de que o autor e as autoras fazem uso como parte indissociável no trabalho com a política e o processo dela em ação. Todavia, há uma sensação de incompletude devido ao exíguo tempo para trabalhar outros temas, explorar os dados de outras maneiras, utilizar outros recursos e até mesmo outras interpretações.

No segundo momento o livro nos convida a levar o contexto a sério. O fato de que as dimensões do contexto são elementos fulcrais na atuação da política é um fato óbvio, tanto para os governos quanto para os acadêmicos; todavia o livro relata que tais elementos tendem a serem negligenciados). Assim, defendendo que “a política cria o contexto, mas o contexto também precede a política” (BALL; MAGUIRE; BRAUN, 2016), o autor e as autoras separam em quatro contextos - situados, profissionais, materiais e externos - lembrando que tais contextos podem sobrepor-se ou estar inter-relacionados no processo de gestão da política.

Ball (1994) já se preocupava com a organização e a instituição da “escola” e o significado e a prática do "professor”, ou seja, os contextos locais, realizações e deslocamentos de políticas.

Claramente, dentro da escola e na prática de sala de aula, são os gestores da escola e professores que devem colocar os pedaços juntos - construir sua própria sujeição se quiser. Individualmente e coletivamente, eles devem dar sentido à reforma e práticas que se comprometem seriamente com as mudanças e suas consequências para as relações de trabalho e para o ensino e aprendizagem (BALL, 1994, p. 12). 
Dando continuidade ao capítulo dois, o autor e as autoras defendem que essas dimensões contextuais da atuação da política servem como catalisador no processo de análise para entender como os compromissos, valores e formas de experiências existentes influenciam na atuação das políticas, ou seja, colocam em evidência as condições reais que os contextos possuem de atuar uma determinada política de acordo com as dinâmicas existentes, suas condições materiais, estruturais e relacionais.

Os contextos situados referem-se a aspectos históricos e localmente intrínsecos à escola, enquanto que os contextos das culturas profissionais focam no conjunto dos costumes e hábitos fundamentais, no âmbito do comportamento (instituições, afazeres etc.) e da cultura (valores, ideias ou crenças), buscando entender se e como eles interferem na atuação das políticas; os contextos materiais versam sobre os recursos materiais, tecnológicos, financeiros e humanos; por fim, os contextos externos levam a buscar as expectativas sobre resultados e responsabilidades dos órgãos reguladores, bem como os investimentos provenientes do governo em relação a outras escolas.

Fechando o capítulo empregam a defesa de que cada contexto é único e está em constante mudança e que, por esse motivo, o modelo apresentado na obra não é abrangente o suficiente para capturar uma imagem do contexto em sua totalidade de forma a ser aplicado em outros contextos; seguindo as premissas dos resultados apresentados na obra, cada investigação irá ver apenas uma pequena fração da realidade existente no contexto de uma ampla gama de fatores.

Fazendo atuação: pessoas, significados e trabalho com políticas é o terceiro capítulo da obra. O foco do autor e autoras é no aspecto hermenêutico das políticas, ou seja, no processo de interpretação e tradução, que por sua vez faz parte da construção de significados que acontecem situados nos contextos das escolas. Para explicar a construção dos significados Ball, Maguire e Braun (2016) optam por uma distinção heurística entre interpretação e tradução, segundo eles, diferentes arenas de atuação da política. A primeira é institucionalizada, uma busca por explicações, esclarecimento para uma construção de interesses da instituição, a ação de tentar compreender as intenções do texto através de uma leitura inicial: “O que esse texto significa para nós? O que temos de fazer? Nós temos de fazer alguma coisa?” (BALL; MAGUIRE; BRAUN, 2016). Já a segunda categoria é o entre-lugar entre a política e a prática, o ato de colocar as políticas em ação de forma prática e concreta, através de reuniões, formações, materiais explicativos ou normativos, que atribuem sentido às políticas, dizem respeito às táticas.

Ball (1994, p. 16) defende: 
[...] as políticas como representações que são codificadas de formas complexas (através de lutas, compromissos, interpretações públicas autorizadas e reinterpretações) e decodificadas de formas complexas (através de interpretações de atores) e significados em relação a sua história, experiências, habilidades, recursos e contexto.

Todavia, em seus escritos anteriores nunca haviam apresentado uma proposta de tipologia, como fez em 1989, com os diretores. O autor e autoras assumem posições diferentes, por meio das quais estabelecem relações diversas com as políticas no processo de atuação. Essa tipologia não é algo findado, permite acréscimos ou mudanças, dependendo dos contextos em que a análise está direcionada. A categoria de atores apresentada define:

- Narradores: Intérpretes responsáveis por explicar a política e decidir o que pode e/ou deve ser feito ou não, o que geralmente é feito pela direção e equipe pedagógica da escola.

- Empreendedores: Atores que defendem a política dentro da escola, que se identificam com os ideais da política e sua atuação, buscam agregar pessoas à política fortalecendo um grupo que possa ajudar no processo de atuação da política.

- Pessoas externas: Sujeitos que não são nem estão na escola, mas possuem relação com determinadas políticas, buscando introduzir novas políticas ou auxiliar no processo de tradução de alguma já existente. Produzem interpretações das interpretações da política tornando-se tradutores na busca por acomodar a política à prática.

- Negociantes: Atuam em dois locais de negociação: o primeiro são os relatos, transcrições e acompanhamento e o segundo é no apoio e facilitação. A ideia é eleger atores (professores) para gerir os dados, num contexto de desconfiança, de forma que se entenda a política através de uma prestação de contas com baixos custos, mesmo que os resultados sejam uma performance. Outro grupo de sujeitos constitui a instância administrativa da escola, são os membros do corpo administrativo, tesoureiros, apoio, especialistas etc.

- Entusiastas e tradutores: Esses sujeitos podem ser as referências para a atuação política; devido à sua influência e à forma como colocam a política em prática, são verdadeiros protótipos, ou seja, matriz da nova política em ação. Essa relação que 
possuem lhes dá uma experiência prática com a política capaz de coletar pessoas para o projeto, pois falam do lugar mais conhecido por todos, a prática.

- Críticos: Um dos principais sujeitos que podemos elencar aqui são os sindicatos. Contribuem para a atuação da política na medida em que a tradução da política coloca em xeque interesses e direitos dos membros que fazem parte da instituição. Dois momentos necessitam de destaque: o monitoramento da atuação das políticas em detrimento das condições de trabalho e bem-estar dos professores; o segundo diz respeito à manutenção do contradiscurso; ambos devem ser considerados no processo de análise dos críticos na atuação das políticas.

- Receptores: Essa categoria é composta por professores iniciantes e assistentes de professores; para o autor e autoras, têm forte tendência de depender de interpretação da interpretação, tornando-se consumidores no trabalho de tradução.

Para encerrar o capítulo o autor e as autoras entendem que a atuação das políticas atribui sentidos à resolução de um problema: comprometer-se com a "melhoria” de tal forma que os atuantes da política possam fazer do compromisso com a política parte de suas carreiras profissionais. Tais atuantes, por sua vez, estão em espaço e arenas diferentes nas (in)coerências da política e suas variâncias entre a interpretação e a tradução; por isso não podem ser considerados iguais. Para deixar tudo mais complexo ainda, não temos apenas uma política sendo atuada na escola, são diversas, que estão em locais, formas e tempos diferentes. Algumas se conectam ou se repelem ou se sobrepõem, bricolagens que exigem dos atuantes uma ação criativa, coletiva, mas limitada, verdadeiros malabarismos que buscam satisfazer os desejos da política, ao invés de criar soluções ideais para cada contexto. Nesse sentido, considera-se que atuação é sempre mais ampla do que “implementação", por reunirem especificidades dos contextos, tais como: históricos e sociais.

Direcionando-se aos dados, Ball, Magueri e Braun (2016) intitularam o capítulo quatro de Sujeitos da política: criatividade restrita e tecnologia de avaliação nas escolas. Sendo os capítulos anteriores mais teóricos, este pretende explorar como as políticas nacionais percorrem o sistema escolar e são encenadas pelas escolas e seus atores por meio da deliverology (cadeia de entrega). Para isso, são apresentadas as experiências de quatro escolas,a fim de elevar os índices mínimos em inglês e matemática.

Enfatiza-se que as políticas não são encenadas de maneira isolada, mas são entendidas como ações situadas oriundas de interações que são resultados de outras agências. Dessa forma, assume- 
se que “diferentes tipos de política interpolam diferentes tipos de sujeitos da política” (BALL; MAGUERI; BRAUN, 2016, p.105). Para tal, utilizam-se do preconizado nos capítulos anteriores, a teoria da atuação das políticas (policy enactment). O objetivo do capítulo é a política de padrões, para demonstrar que diferentes políticas são atuadas nas escolas e necessitam de diferentes tipos de atores, e esta, particularmente, tem sido utilizada pelos governos como mecanismo eficaz de “orientação” a distância. “Os espaços de negociação e de contestação da política são relativa e estreitamente definidos aqui, dominados, em sua maior parte, pela necessidade e pela responsabilidade de os professores 'fazerem o seu melhor'” (BALL; MAGUIRE; BRAUN, 2016, p. 106).

Continuando as discussões do capítulo, o autor e autoras se interessam pelos padrões como um conjunto de práticas sofisticadas produzidas internamente ao processo de interpretação e tradução, compreendem o estabelecimento de um sistema de regulação da educação que estabelece os vínculos entre as salas de aula e o padrões macro, em que os sujeitos para se tornarem atuantes carecem de um processo de treinamento para a correção de suas ações, chegando a passar por uma classificação ou exclusão, em outros termos, é a produção de corpos educados e mentes "produtivas".

Ainda nesse capítulo apresentam como instrumentos conceituais a possibilidade de textos legíveis e escrevíveis (readerly e writerly), eficazes em dar conta dos padrões, pois,

O texto Readerly (legível) pressupõe e depende de presunções de inocência, na crença de que o leitor terá muito pouco a oferecer por meio de uma alternativa. [...] Por último, Barthes sugere que a leitura de textos writerly (escrevível) envolve dois tipos de 'prazer' direto, o prazer da leitura e o gozo, o êxtase ou felicidade que surgem a partir do sentido de avaria ou de interrupção. Estes últimos provenientes da resposta crítica e criativa para além do texto. [...] Também é vital reconhecer que estes textos, writerly (escrevível) e readerly (legível), são os produtos de um processo da política, um processo que já indicamos que emerge em contínua interação com uma variedade de contextos inter-relacionados (BOWE; BALL; GOLD, 1992, p. 11-12, tradução nossa).

Para ampliar estes conceitos os relacionam ao que chamaram de políticas imperativas/disciplinares e políticas exortativas/ de desenvolvimento. Para as políticas interpretativas teremos sujeitos mais passivos, preocupados com as técnicas e na prática da política, ou seja, nos resultados do processo de atuação. Em contrapartida, as políticas exortativas são 
capazes de formar sujeitos mais críticos, que constroem e questionam as políticas e suas impossibilidades nos diferentes contextos engajados na aprendizagem em profundidade dos alunos.

Encerrando o capítulo problematizam esse tipo de política com pouca oportunidade para a atribuição de sentidos, onde são bem limitadas as ações por um conjunto de mecanismos e tecnologias, fortalecendo o argumento das combinações políticas entre atores, textos e objetos. Além disso, o autor e as autoras destacam o papel dos artefatos da política como elementos fundamentais e integradores de ações e espaços (cadeia de entrega) nas políticas.

Outra política que analisam com mais detalhe e aprofundamento é a política de comportamento. No capítulo intitulado Fazendo política de comportamento na escola, Ball, Maguire e Braun (2016) introduzem uma discussão sobre os mecanismos que as escolas desenvolvem para regular a recontextualização das políticas e do comportamento dos estudantes. Focam na ideia de “disciplina” como discurso que circula na escola e nas políticas imbricadas nas relações de poder, que traz à escola a exigência de abordar tal tema de forma integral, necessidade que surge da grande ocorrência do termo “comportamento” nas análises dos dados coletados nas 95 entrevistas. Em destaque trazem que esse termo é utilizado pela direita e esquerda para mostrar que a educação é prioridade.

Como nas suas obras anteriores, Como as escolas fazem a política é uma obra em que o autor e as autoras utilizam dados empíricos da pesquisa para demonstrar a sua teoria no processo de análise. A política de comportamento é um tema que trazem de forma inovadora para a reflexão dos dados; “como a avaliação e padrões, a política de comportamento é também uma arena chave para a oportunidade de negócios” (BALL; MAGUIRE; BRAUN, 2016, p. 142). A atuação de tais políticas resulta em modas e técnicas diferentes que são comercializadas e distribuídas pelas escolas.

No capítulo Artefatos da Política: discursos, representações e traduções, o autor e as autoras buscam chamar a atenção para a importância dos artefatos nos processos de atuação das políticas nas escolas, sobretudo por meio da produção de materiais visuais e recursos que direcionam, circulam, reforçam e representam o discurso da "boa” escola. A “boa” escola no texto é entendida como aquela que atende a uma conduta ideal ou desejável.

Os artefatos são entendidos como parte das ferramentas e técnicas de governabilidade no trabalho de política na escola ao ponto de representar produções culturais que carregam conjuntos de crenças e significados. O autor e as autoras destacam, a partir dos casos e situações apresentadas, que os artefatos contribuem para "fazer” escola por meio da produção e reprodução de sinais, significantes e símbolos das políticas; de artefatos culturais (manuais, boletins, websites, diários 
etc.); e de conjuntos de atividades (reuniões, eventos etc.). Os autores evidenciam a necessidade de produção desses artefatos como estratégias:

O processo de produzir/fazer conjuntos de ideias sobre as políticas que se tornam parte do "tidas-como-evidente" da escola envolve, frequentemente, a produção de representações e de traduções, simulacros de textos de políticas primários (BALL; MAGUIRE; BRAUN, 2016, p. 171).

O autor e as autoras destacam que nas quatro escolas estudadas é forte a presença dos artefatos visuais que abordam questões políticas. As escolas estudadas apresentavam táticas e estratégias que adotavam elementos visuais discursivos e artefatos que reforçam e reproduzem as ideias de bom/mau aluno/professor/escola pautadas nos ideais de performance e desempenho. Nas escolas estudadas, os artefatos possuem um papel fundamental no estabelecimento e normalização das práticas. Por esse motivo, no texto é enfatizado que as políticas não são possíveis sem os artefatos; ademais, os atores humanos e não humanos se entrelaçam nos processos de atuação política.

No livro é ressaltada a ausência de literatura no que se refere ao papel dos artefatos visuais e culturais na promoção da consciência dos professores sobre a política e suas práticas no ambiente escolar ou como atuantes “não humanos” no processo de política. No entanto, podem-se destacar alguns estudos que têm dedicado atenção à ação e ao papel dos artefatos na pesquisa em educação (FENWICK; EDWARDS; SAWCHUCK, 2012), políticas educacionais (LANDRI, 2014) e gestão escolar (MOURA; BISPO, 2016). Esses estudos têm como base teórica e epistemológica abordagens que consideram a importância dos elementos “não humanos” para a pesquisa em educação.

No último capítulo, Em direção a uma teoria de atuação o autor e as autoras fazem um exercício de reunir as respostas à questão teórica e empírica acerca de "Como as escolas fazem política”. Para isso, discutem a teoria da atuação não como uma "receita” de como implementar política, mas sim, como uma maneira de refletir criticamente o padrão instrumental e prescritivo adotado nas implementações das políticas. Ressaltam a impossibilidade de produzir um modelo ideal, linear e único de atuação das políticas. As escolas têm o desafio de atuar políticas múltiplas e competitivas em contextos situados e complexos.

Nesse sentido, é retomada no texto a importância da diferenciação entre os termos implementação e atuação de políticas. Essa diferenciação busca chamar atenção para a ausência de iniciativas de compreender e documentar as maneiras pelas quais as escolas realmente lidam com as suas demandas de políticas no cotidiano em função de suas realidades situadas e contextuais. 
Ainda no mesmo capítulo discutem que a compreensão do processo de atuação das políticas depende de como a política é teorizada; o processo de elaboração de política nas escolas se torna um conjunto complexo de processos de interpretação e tradução, contextualmente mediados e institucionalmente concebidos.

A teoria da atuação nos envolve na busca por compreender o contexto escolar como um espaço de complexidade produzido por redes de pessoas, artefatos e práticas. Dessa forma, percebese que as escolas são espaços diferentes bem como são produtos do seu contexto e influenciados por aspectos sociais, estruturais e pelo seu entorno.

A TAR, abordagem utilizada para análise da política nos casos estudados, oferece um suporte teórico para compreender como essas redes de atores se conectam e interagem no contínuo e recursivo processo de “fazer” política. Além disso, orienta para uma análise da política que considera o papel de diversos atores, superando a ideia de implementação de políticas centrada na figura de poder do diretor ou dos líderes seniores.

Por fim, o autor e as autoras apresentam pontos que não são tocados no trabalho ou foram abordados de maneira superficial, mas que podem ser elementos a serem perseguidos futuramente como: a ideia de narração; as relações de política e contexto material; e o trabalho de política de tradução e as suas diferentes formas e práticas. Além disso, apontam "próximos passos” que podem contribuir para futuros debates em torno da atuação da política, que são: a necessidade de levar o contexto de maneira mais séria na análise das políticas; elementos inibidores ou facilitadores da atuação política; atenção à “complexidade desorganizada” das escolas, evitando “teorias de cima”; apresentação de casos atípicos ou extremos da atuação de políticas; e a relação entre poder, agência e espaço para alternativas.

A contribuição da obra para o campo das pesquisas em educação está em uma caixa de ferramentas metodológicas e teóricas original, potencializando a investigação da atuação das políticas em toda sua complexidade, isto é, considerando elementos que muitas vezes são entendidos como secundários na formulação e atuação das políticas: como o papel desempenhado pelos diferentes atores, a agência exercida pelos artefatos produzidos para e pelas políticas, o contexto situado e específico de cada escola etc. Assim, fica o convite à leitura dos diversos atores (formuladores da política, pesquisadores, professores, gestores, alunos, entre outros) que, direta ou indiretamente, investigam e colocam as políticas educacionais em prática. 


\section{REFERÊNCIAS}

BALL, Sthephen J. Education Reform: a critical an post-structural approach. Philadelphia: Open University Press, 1994.

. La micropolítica de la escuela. Hacia una teoría de la organización escolar. Tradução de Néstor Míguez. Madrid: Paidos, 1989. 297 p. ISBN 84-7509-529-1.

BOWE, R.; BALL, S. J.; GOLD, A. Reforming Education and Changing Schools: Case Studies in Policy Sociology. London: Routledge, 1992. 188 p. ISBN 0-415-07789-3.

FENWICK, T; EDWARDS, R.; SAWCHUK, P. Emerging approaches to educational research: tracing the sociomaterial. Routledge, 2011.

LANDRI, P. The sociomateriality of education policy. Discourse: Studies in the Cultural Politics of Education, 2014.

MOURA, E.; BISPO, M. A textura da gestão escolar como prática social. In: EnANPAD, 2016, Salvador. Anais eletrônicos... Salvador: ANPAD, 2016. Disponível em: <http://www.anpad.org.br/ anpad/eventos.php?cod_ evento=1\&cod_evento_edicao=83\&cod_edicao_subsecao=1302\&cod_edicao_trabalho=21136 $>$. Acesso em: 29 jul. 2018. 